Revista Tecné, Episteme y Didaxis: TED. Año 2014, Número Extraordinario. ISSN Impreso: 0121-3814, ISSN web: 2323-0126 Memorias, Sexto Congreso Internacional sobre Formación de Profesores de Ciencias. 08 al 10 de octubre de 2014, Bogotá

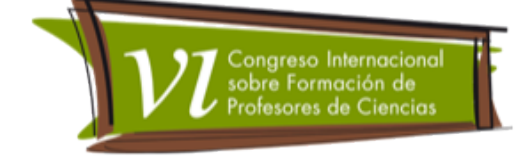

\title{
Copérnico vs Ptolomeu: Discutindo a natureza da ciência no ensino médio
}

Costa Gomes, José Leandro de Albuquerque Macedo'

Categoria 1. Pensamentos e experiências de inovação na sala de aula.

\section{Resumo}

Descreve-se o planejamento e execução de um plano de aulas para o $2^{\circ}$ ano do ensino médio do Brasil, o qual objetivou levar a discussão sobre aspectos da Natureza da Ciência à sala de aula. Para isso, fez-se uso da discussão histórica, nos séculos XV e XVI, sobre os modelos copernicano e ptolomaico para o sistema solar. Foram observadas mudanças nos perfis conceituais dos discentes sobre o fazer científico.

\section{Palavras-chave}

Natureza da Ciência; Sistema Solar; Ensino Médio.

\section{Introdução}

A discussão sobre a forma de se abordar a Natureza da Ciência (NdC) em sala de aula e sua relação com as metodologias de ensino das ciências utilizadas nas escolas tem ocorrido faz décadas. Muitos estudos teóricos e alguns empíricos foram publicados. No entanto, pouco foi produzido sobre as vivências em sala de aula que exploram aspectos da $\mathrm{NdC}$ a fim de estabelecer um perfil conceitual mais adequado sobre o fazer científico com os discentes do ensino básico.

Um dos estudos mais divulgados no meio acadêmico foi o de Gil-Pérez et al. (2001). Tal escrito partiu de uma análise do labor de docentes do ensino básico e como estes percebiam a Ciência e suas caraterísticas. Identificaram visões inadequadas com respeito à NdC: a socialmente neutra, a acumulativa, a elitista e individualista, a exclusivamente analítica, a ateórica, a rígida e algorítmica e a aproblemática e ahistórica.

Todavia, Gil-Pérez et al. (2001) não trazem contribuições profundas no tocante à prática em sala de aula, e poucos foram os estudos derivados que se dedicaram às situações didáticas que promovessem o debate sobre tais visões

\footnotetext{
1 Instituto Federal de Alagoas - Campus Arapiraca; prof.leandro.fisica@hotmail.com
} 
Revista Tecné, Episteme y Didaxis: TED. Año 2014, Número Extraordinario. ISSN Impreso: 0121-3814, ISSN web: 2323-0126 Memorias, Sexto Congreso Internacional sobre Formación de Profesores de Ciencias. 08 al 10 de octubre de 2014, Bogotá

deformadas com os educandos do ensino básico. Este trabalho traz o planejamento e execução de um plano de aulas que fez uso de episódio histórico da Física para explorar aspectos da $\mathrm{NdC}$ com discentes do $2^{\circ}$ ano do ensino médio brasileiro.

\section{A natureza da ciência}

Diversas pesquisas realizadas buscaram descrever as linhas gerais sobre quais seriam as características do fazer científico. Feita análise, pode-se perceber certos aspectos da $\mathrm{NdC}$, tais como:

a) A transitoriedade dos conhecimentos;

b) A falibilidade das teorias e construções conceituais da ciência;

c) A imersão do ser no saber e do saber no ser numa recíproca e contínua mutação de ambos;

d) A ideia primeira como contingenciadora do observar e pensar sobre o fenômeno;

e) A ação do intelecto (ser) sobre o concreto (fenômeno) na produção de um abstrato (conceito) manipulável em sua totalidade no pensamento;

f) O dissenso como instância partícipe na produção de conhecimento;

g) A multiplicidade de métodos ao se fazer ciência;

h) A coletividade da construção da ciência;

i) A coerência dos constructos teóricos para explicação dos fenômenos à época em que foram desenvolvidos.

(Costa Gomes, 2013, pág. 28).

Pensando na necessidade de promover a adequação dos perfis conceituais dos educandos com relação ao fazer científico, um plano de aulas interdisciplinar foi idealizado, partindo da discussão histórica, nos séculos XV e $\mathrm{XVI}$, sobre os modelos ptolomaico e copernicano para a descrição do sistema solar, visando explorar os aspectos da NdC a, b, f, h e i supracitados. Com isto, buscou-se confrontar as visões a socialmente neutra, a acumulativa, a elitista e individualista, a rígida e algorítmica e a aproblemática e ahistórica.

\section{O episódio histórico}

Historicamente, o debate entre os citados modelos ganhou pujança em meados do século XVI com a publicação da principal obra de Copérnico (Séc. XVI), De Revolutionibus Orbium Coelestium (1543). Até então, e por 
Revista Tecné, Episteme y Didaxis: TED. Año 2014, Número Extraordinario. ISSN Impreso: 0121-3814, ISSN web: 2323-0126 Memorias, Sexto Congreso Internacional sobre Formación de Profesores de Ciencias. 08 al 10 de octubre de 2014, Bogotá

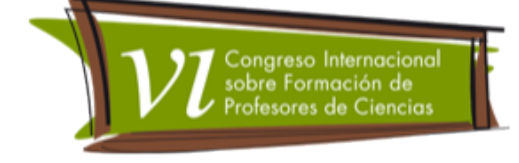

diversas razões, a descrição dada por Ptolomeu (Séc. I) para os movimentos dos corpos celeste era bem aceita tanto no meio acadêmico quanto no religioso, principalmente por estar alinhada aos pensamento aristotélicos. Entretanto, a matemática necessária ao modelo ptolamaico era bastante complexa.

A contribuição de Ptolomeu aos estudos dos movimentos do corpos celestes foi de grande relevância. O Almagesto, do início do século II, traz o esforço monumental realizado por tal pensador em sua busca pela descrição precisa para o sistema de corpos celestes. Nesse escrito, Ptolomeu adota a Terra em estado de repouso, caracterizando o sistema com geostático, mas não a considera como o ponto central a partir do qual todos os outros orbes tem seu referencial de movimento. Aliás, a informação de que o modelo de Ptolomeu é geocêntrico é amplamente divulgada nos manuais de ensino e livros didáticos no Brasil (Martins, 1994).

Ptolomeu lança mão de vários artifícios matemáticos para conseguir descrever satisfatoriamente os movimentos visto da Terra e ainda conciliar tais explicações com os parâmetros e princípios filosóficos gregos. Se por um lado tais artifícios agregam grande complexidade matemática, por outro obteve grande êxito, pois além de conseguir explicar os movimentos mais exóticos, como as laçadas planetárias, também mantinha as trajetórias circulares que estavam associadas à perfeição, ideia intensamente defendida entre os pensadores clássicos da Grécia Antiga. Estes sucessos conferiram longevidade ao modelo ptolomaico, mesmo havendo intensas discussões entre os matemáticos quanto a acurácia do modelo, o qual apenas seria fortemente confrontado cerca de catorze séculos depois de sua publicação.

Por volta do século XIV, muitos dos textos de Aristóteles e Platão estavam sendo novamente estudados e repensados, principalmente entre os pensadores dos primeiros centros de ensino. Muito disso é devido à habilidade de alguns pensadores ligados à Igreja que conseguiram conciliar os dogmas religiosos com os estudos produzidos por pensadores da Antiguidade (Martins, 1994).

A maior precisão dos dados astronômicos colhidos ao longo dos séculos mostraram discrepâncias entre as previsões baseadas no modelo ptolomaico. Junte-se a isto a discordância entre os matemáticos se o modelo de Ptolomeu era ou não exequível. Aqui parecem residir as duas principais motivações para Copérnico estudar e publicar um modelo alternativo. 
Revista Tecné, Episteme y Didaxis: TED. Año 2014, Número Extraordinario. ISSN Impreso: 0121-3814, ISSN web: 2323-0126 Memorias, Sexto Congreso Internacional sobre Formación de Profesores de Ciencias. 08 al 10 de octubre de 2014, Bogotá

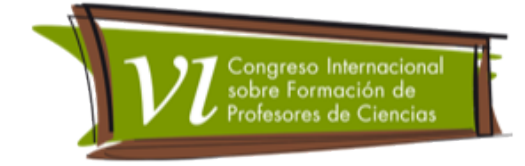

Para Copérnico, ao planeta Terra seriam atribuídos inicialmente dois movimentos, os que hoje são chamados de rotação e translação. Além disso, tal pensador dispôs os corpos celestes conhecidos até então na seguinte sequência, em ordem de afastamento em relação ao Sol: Mercúrio, Vênus, Terra, Marte, Júpiter, Saturno, Estrelas Fixas. Ao que parece, a tese defendida por Copérnico era a de que, se conferido movimento a Terra e aos outros corpos celestes e com o Sol estático, as trajetórias percebidas por observadores na Terra seriam mais facilmente explicadas e descritas por uma matemática mais simples. O que, de fato, ocorreu (Copérnico, 2003).

A conformação dada por Copérnico à descrição dos movimentos e posições relativas dos corpos celeste pode ter sido inspirada, em sua época de universidade, pelas leituras das obras de Platão, o qual adotava ideias pitagóricas, como a do movimento terrestre (Martins, 1994).

Tais ideias foram em rota de colisão com a visão dogmática da lgreja, a qual aceitava a descrição física do mundo sublunar segundo o aristotelismo e a explicação ptolomaica do mundo supralunar. Além disso, por ter se concentrado na descrição matemática mais simples e não conseguido abordar profundamente as próprias advertências que fazia ao aristotelismo, seu modelo acabou relegado às prateleiras, tido apenas como mais uma descrição matemática dos movimentos celestes (Martins, 1994).

Estudo posteriores de outros pensadores corroboraram a ideia de que um sistema heliostático seria mais eficiente na explicação e descrição das trajetórias e organização dos corpos celestes.

\section{O plano de aulas: descrição, discussão e resultados}

Fundamentado na controvérsia histórica apresentada, professores das áreas de Física, História, Geografia e Matemática planejaram uma semana didática na qual todas as aulas dessas disciplinas fossem direcionadas à discussão sobre tais modelos. Dessa forma, foi desenvolvido um conjunto de aulas, a fim de instigar os educandos a investigarem tal discussão histórica.

No total foram realizados dez momentos didáticos, cada um com cinquenta minutos e todos vivenciados em uma turma do $2^{\circ}$ ano do ensino médio de uma escola pública, com 40 discentes, com idades entre catorze e dezessete anos, de ambos os sexos.

No $1^{\circ}$ momento, foram exploradas as concepções prévias dos educandos sobre sistema solar. Os discentes foram incentivados a externarem suas 
Revista Tecné, Episteme y Didaxis: TED. Año 2014, Número Extraordinario. ISSN Impreso: 0121-3814, ISSN web: 2323-0126 Memorias, Sexto Congreso Internacional sobre Formación de Profesores de Ciencias. 08 al 10 de octubre de 2014, Bogotá

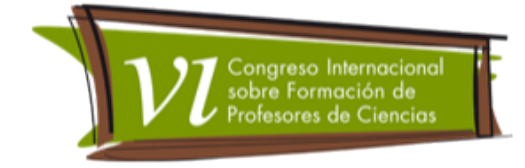

opiniões e houve entre eles a unanimidade de que o modelo atual era 0 copernicano e heliocêntrico. Em sequência, no $2^{\circ}$ momento foram apresentadas as descrições sobre o que seria um modelo heliocêntrico e o um geocêntrico. Ao fim, os educandos foram divididos em 8 grupos de 5 discentes e a eles foi dada a incumbência de pesquisarem sobre os modelos ptolomaico e copernicano para, três dias após, apresentarem uma dissertação de uma página e meia (no modelo-padrão do word). Esses dois momentos foram executados pelos professores de Física e Matemática.

No dia seguinte, foram vivenciados os momentos 3 e 4, coordenados pelos professores de História e Geografia. Foram explorados e discutidos com os discentes os aspectos sociais, culturais, econômicos e religiosos da Europa do séculos XV e XVI. Inicialmente, um texto-resumo da situação europeia, produzidos pelos professores, foi entregue aos educandos. As informações contidas foram debatidas, com o objetivo de levar os discentes a perceberem se os parâmetros sociais exerceriam ou não influência na produção científica. Houve intenso debate. $40 \%$ da turma defendia que não há relação entre ciência e sociedade, 35\% relação fraca, 15\% relação íntima, e 10\% não opinaram.

Dois dias depois, os educandos iniciaram $\circ 5^{\circ}$ momento entregando as dissertações construídas em colaboração. Como planejado, os próprios discentes iniciaram um debate entre si sobre os conceitos heliocêntrico $x$ heliostático e geocêntrico $\times$ geostático. Essa debate foi o estopim para os professores de Matemática e História começarem a abordar tais temas: um pelo viés geométrico e outro pela perspectiva histórica, que tomou os momentos 6 e 7. Os docentes intercalaram suas falas, direcionando-as às épocas e aos pensadores abordados. Primeiro à Antiguidade, depois ao Medievo, e, por fim, ao Renascimento. As intervenções objetivaram enfatizar a contribuição de vários pensadores e as duas linhas de pensamento concorrentes quanto ao modelo de sistema solar. Ao fim, os discentes foram novamente arguidos quanto a relação sociedade-ciência, sendo aferidos os percentuais: $20 \%$ não há relação, 20\% relação fraca, 55\% relação íntima, e 5\% não opinaram. Além disso, foram incentivados a discutir sobre a influência de outros pensadores sobre a produção de Copérnico e de Ptolomeu. Seis discentes chegaram a levantar a hipótese se "era justo chamar modelo copernicano e modelo ptolomaico, já que tanto um como o outro usaram ideias de outras pessoas?" (Discentes 1, 7, 11, 12, 28 e 33).

Os 3 últimos momentos, realizados no dia seguinte, foram coordenados pelos professores de Física e Geografia. Os trabalhos foram iniciados perguntando-se aos discentes sobre qual seria o modelo atualmente aceito. Houve certa 
Revista Tecné, Episteme y Didaxis: TED. Año 2014, Número Extraordinario. ISSN Impreso: 0121-3814, ISSN web: 2323-0126 Memorias, Sexto Congreso Internacional sobre Formación de Profesores de Ciencias. 08 al 10 de octubre de 2014, Bogotá

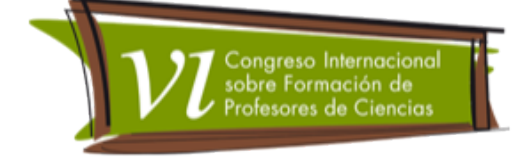

discussão, rápida, até a intervenção do docente de Geografia, que passou a explicar o modelo atual. Depois, o professor de Física lançou a questão por que um modelo que explicava relativamente bem as situações e que foi aceito por quase 1500 anos foi deixado de lado? Várias respostas foram dadas, destacando-se uma "ora, porque conhecimento passa. Daí vem outro que é mais abrangente, que dá conta de explicar mais coisas, e mais fácil" (DISCENTE 12), a qual fez a discussão encerrar e os discentes concordarem. Então, outra questão foi lançada aos educandos, então, o modelo que ficou para trás estava errado? Várias respostas foram dadas, das quais destacou-se uma que novamente encerrou os debates:

Errado, não. Tipo assim, o que eu pensava há dois anos valia pra mim, Agora, penso diferente, e também vale. Acho que na Ciência é do mesmo jeito. As ideias mudam, se transformam. Hoje é uma coisa; amanhã é outra" (DISCENTE 33).

Todos os momentos foram registrados em 2 diários construídos simultânea e separadamente pelos dois docentes que estavam ociosos em cada momento didático. Depois foi feita a compilação e análise dos mesmos.

\section{Conclusões e desdobramentos}

Todos os docentes envolvidos concordam que os momento foram ricos e que os educandos se envolveram fortemente nas atividades e debates.

Pelos falas registradas e posteriores conversas, foi possível perceber significativa readequação dos perfis conceituais dos educandos quanto aos aspectos da NdC objetivados.

Tenciona-se agora aprimorar o plano de aulas a fim de executá-lo em outras turmas.

\section{Referências bibliográficas}

Copérnico, N. (2003). Commentariolus. Edição comentada de Roberto de Andrade Martins. (2nd ed.). São Paulo: Editora Livraria da Física. (Original publicado em 1543).

Costa Gomes, J.L.A.M. (2013). Conceito de Calor: Debate histórico e proposta para a sala de aula. Dissertação de mestrado em história e filosofia da ciência, Centro de Ciências e Tecnologia - Universidade Estadual da Paraíba, Brasil. 
Revista Tecné, Episteme y Didaxis: TED. Año 2014, Número Extraordinario. ISSN Impreso: 0121-3814, ISSN web: 2323-0126

Memorias, Sexto Congreso Internacional sobre Formación de Profesores de Ciencias. 08 al 10 de octubre de 2014, Bogotá

Gil-Pérez, D.; et al. (2001). Para uma Imagem não Deformada do Trabalho Científico. Ciência \& Educação, 7 (2), pág.125-153.

Martins, R.A.; O Universo. Teorias sobre sua origem e evolução. (1994). São Paulo: Editora Moderna. 